\title{
Evaluation and improvement of soil water characteristic curves through in-situ monitoring data in the plains
}

\author{
Pingnan Zhang ${ }^{1}$, Chuanhai Wang ${ }^{1}$, Gang Chen ${ }^{1}$, Shiwei Zheng ${ }^{1}$, Yue $\mathrm{Yu}^{1}$, Youlin $\mathrm{Li}^{1}$, and \\ Xiaoning $\mathrm{Li}^{1}$ \\ ${ }^{1}$ Hohai University College of Hydrology and Water Resources
}

February 16, 2022

\begin{abstract}
In the agricultural area of humid plains, soil water migration and exchange events are frequent and disruptive. Studies on the soil water characteristic curve (SWCC) of unsaturated zones show they are significantly impacted by regional water cycles. In this study, a variety of hydrological data parameters such as rainfall, evaporation, soil water content, and groundwater level were continuously collected for Jintan experimental site in the plains of Taihu Basin, China. The observation results show that the soil water content changes drastically in the flood season every year, with the occurrence of obvious absorption and desorption processes. In terms of soil water content, the soil layer corresponding to a depth of 0-40 $\mathrm{cm}$ below the ground is the zone that is most frequently and severely altered. The SWCC based on field data was obtained through numerical inversion of soil water characteristic parameters in a numerical code (HYDRUS-1D). Compared with those measured in the laboratory, the field measured curves in each depth range are more consistent with the characteristics of silty clay loam. The SWCC from field data and the laboratory data were each applied to simulate soil water content for different depths in precipitation events. The simulation results based on the field data showed significantly better correspondence than the results of the laboratory simulation and were more consistent with the changes in soil water content measured in the field.
\end{abstract}

\section{Hosted file}

SWCC-Manuscript-2.docx available at https://authorea.com/users/460843/articles/556709evaluation-and-improvement-of-soil-water-characteristic-curves-through-in-situmonitoring-data-in-the-plains 